Article

\title{
ALT Trends through Childhood and Adolescence Associated with Hepatic Steatosis at 24 Years: A Population-Based UK Cohort Study
}

\author{
Ahlia Sekkarie ${ }^{1, *(D)}$, Jean A. Welsh ${ }^{1,2}$, Kate Northstone ${ }^{3}$, Catherine E. Cioffi ${ }^{2}(\mathbb{D}$, \\ Aryeh D. Stein ${ }^{1,4}{ }^{D}$, Janet Figueroa ${ }^{2}$, Usha Ramakrishnan ${ }^{4}$ and Miriam B. Vos ${ }^{1,2}$ \\ 1 Laney Graduate School, Emory University, Atlanta, GA 30322, USA; jwelsh1@emory.edu (J.A.W.); \\ aryeh.stein@emory.edu (A.D.S.); mvos@emory.edu (M.B.V.) \\ 2 Department of Pediatrics, Emory School of Medicine, Atlanta, GA 30322, USA; \\ catherine.cioffi@emory.edu (C.E.C.); janet.figueroa@emory.edu (J.F.) \\ 3 Population Health Science, Bristol Medical School, Bristol BS8 2BN, UK; Kate.Northstone@bristol.ac.uk \\ 4 Hubert Department of Global Health, Rollins School of Public Health, Emory University, \\ Atlanta, GA 30322, USA; uramakr@emory.edu \\ * Correspondence: a.sekkarie@gmail.com
}

Received: 4 August 2020; Accepted: 27 August 2020; Published: 1 September 2020

check for updates

\begin{abstract}
Background: Alanine aminotransferase (ALT) is used to screen for non-alcoholic fatty liver disease (NAFLD) in children; however, the optimal age to commence screening is not determined. Our objective was to describe whether ALT trends from 9-24 years were associated with hepatic steatosis at 24 years in a population-based UK cohort. (2) Methods: The sample included 1156 participants who were assessed for hepatic steatosis at 24 years and had at least two ALT measurements at $9,15,17$, and/or 24 years. Controlled attenuation parameter scores were used to assess steatosis (low $(<248 \mathrm{~dB} / \mathrm{m})$, mild/moderate $(248-279 \mathrm{~dB} / \mathrm{m})$, severe $(>279 \mathrm{~dB} / \mathrm{m})$ ). Sex-stratified mixed-effects models were constructed to assess the liver enzyme trends by steatosis level. (3) Results: The final sample was $41.4 \%$ male and $10.4 \%$ had severe steatosis. In both sexes, ALT trends from 9 to 24 years differed in those with low vs. severe steatosis at 24 years $(p<0.001)$. There was no evidence of differences prior to puberty. At 17 years, the low vs. severe geometric mean ratio (GMR) was 0.69, 95\% CI: $0.57-0.85$ in males and $(0.81,0.65-1.01)$ females. At 24 years, the GMR was $(0.53,0.42-0.66)$ in males and $(0.67,0.54-0.84)$ females. (4) Conclusions: Higher ALT concentration in adolescence was associated with hepatic steatosis at 24 years. The increased screening of adolescents could strengthen NAFLD prevention and treatment efforts.
\end{abstract}

Keywords: NAFLD; ALT; childhood; longitudinal; ALSPAC

\section{Introduction}

Non-alcoholic fatty liver disease (NAFLD) is the hepatic manifestation of metabolic syndrome [1]. NAFLD is defined as having steatosis involving greater than 5\% hepatocytes, typically assessed by liver biopsy or imaging, in the absence of other causes of hepatic steatosis including heavy alcohol intake [2]. Established risk factors for NAFLD include age, male sex, and obesity. The prevalence of NAFLD has increased considerably over recent decades in youth in parallel with the rise of obesity [3]. This is concerning because pediatric NAFLD can progress to nonalcoholic steatohepatitis (NASH), which is characterized by inflammation, as well as cirrhosis and end stage liver disease in adulthood [4]. NAFLD is also associated with an increased risk of diabetes, cardiovascular disease and pregnancy complications $[5,6]$. 
The onset and subsequent natural history of NAFLD in childhood and adolescence is not well characterized [2]. Despite reports of infants with hepatic steatosis [7-10], little is known about the disease in pre-pubertal children. Most children with NAFLD typically present clinically between 10 to 13 years old [11]. If the disease is caught early, outcomes can be improved through drugs or lifestyle changes, primarily by improving diet quality (e.g., reducing sugar) and increasing physical activity $[2,12]$. Therefore, the ability to detect NAFLD in its earliest stages is crucial to mitigating the consequences of childhood NAFLD.

Currently, the recommended screening method for NAFLD in children includes elevated alanine aminotransferase (ALT) serum concentration, concurrent with obesity and other risk factors for metabolic disease, such as a family history of diabetes [2]. While the other two primary liver enzymes, aspartate aminotransferase (AST) and gamma-glutamyl transferase (GGT) are not used as screening markers for NAFLD in children, they are associated with a worse histology of the disease when they are elevated along with ALT $[2,13]$.

Due to the sparsity of studies on the incidence and natural history of pediatric NAFLD, especially prior to its diagnosis, the ideal age for screening for NAFLD is not known [2]. No studies using serial measurements have been published on the trajectory of liver enzymes from childhood to adulthood. Additionally, the association between liver enzyme trends from childhood into adulthood and the risk of NAFLD has not been previously explored. In this paper, we describe the trends in ALT and other liver enzyme concentrations in the UK population-based Avon Longitudinal Study of Parents and Children (ALSPAC) birth cohort from 9 to 24 years and determine whether these trends differ by category of hepatic steatosis at 24 years.

\section{Materials and Methods}

\subsection{Study Design and Population}

We used the data from a population-based birth cohort study (ALSPAC) based at the University of Bristol (Bristol, UK) that has previously been described in detail [14-16]. Briefly, ALSPAC enrolled 15,454 pregnant women in the greater Bristol area with expected delivery dates between 1 April 1991 and 31 December 1992. Of their children, 14,901 were alive at one year of age. When the offspring were 24 years of age, 10,018 participants were invited to a clinic visit (that wave was known locally as Focus@24) between 5 June 2015 and 31 October 2017, which included the collection of biological samples and anthropometric measures, and 4021 attended. Other waves of fieldwork occurred when the participants were ages seven through 17 years. Data from the 24 year clinic were collected and managed using REDCap electronic data capture tools hosted at the University of Bristol [17,18]. The study website contains details of all the data that are available through a fully searchable data dictionary and variable search tool [19].

Ethical approval for the study was obtained from the ALSPAC Ethics and Law Committee and The data from the 24 Year Clinic was approved by the National Research Ethics Service Committee South West-Frenchay: 14/SW/1173 ALSPAC Focus at 24+ (24 February 2015, confirmed 20 March 2015) Informed consent for the use of collected data via questionnaires and clinics was obtained from participants following the recommendations of the ALSPAC Ethics and Law Committee at the time.

\subsection{Assessment of Liver Outcomes}

Participants were asked to fast overnight or for at least six hours prior to phlebotomy and transient elastography. Blood samples were immediately centrifuged and frozen at $-80^{\circ} \mathrm{C}$. Fasting serum ALT, AST, and GGT liver enzyme concentrations were obtained through standard clinical chemistry assays at ages 9 (non-fasting), 15, 17 and 24 years as previously described [20]. At 24 years, elevated ALT was defined as $>19 \mathrm{U} / \mathrm{L}$ in women and $>30 \mathrm{U} / \mathrm{L}$ in men [21].

At 24 years old, the participants were assessed by transient elastography for the non-invasive quantification of liver steatosis and fibrosis (FibroScan 502 Touch, Echosens, Paris, France). Individuals 
with an active implant, liver ascites, or who were pregnant were excluded from the liver scan. Transient elastography provides a controlled attenuation parameter (CAP) measure of steatosis and a measure of liver stiffness to quantify fibrosis. Manufacturer and machine indications were used to determine whether the $\mathrm{M}$ or $\mathrm{XL}$ probe would be used to conduct the scan. Ten readings were required for each patient to derive a CAP score and fibrosis result. CAP values outside the $100-400 \mathrm{~dB} / \mathrm{m}$ range were considered invalid and coded as missing. Additionally, median fibrosis results greater than or equal to $15 \mathrm{kPa}$ or with an IQR to median ratio greater than or equal to $30 \%$ were considered invalid and coded as missing.

We categorized participants by level of steatosis at 24 years based on CAP scores and using cut-off values derived from a meta-analysis by Karlas, et al. [22]. Low steatosis $(<10 \%)$ was defined as $<248 \mathrm{~dB} / \mathrm{m}$, mild/moderate steatosis $(10-66 \%$ ) was defined as $248-279 \mathrm{~dB} / \mathrm{m}$, and severe steatosis ( $>66 \%$ ) was defined as $>279 \mathrm{~dB} / \mathrm{m}$. We categorized the fibrosis values into two groups. The first group included those with no fibrosis or portal fibrosis without septa (F0-F1, $<7.9 \mathrm{kPA}$ ) and the second group included those with any fibrosis: portal fibrosis, septa, or cirrhosis (F2-F4, >7.9 kPA) [23].

\subsection{Covariates}

We calculated the body mass index (BMI) as weight in kilograms divided by height in meters squared [24]. We classified BMI at 24 years as underweight $\left(<18.5 \mathrm{~kg} / \mathrm{m}^{2}\right)$, normal weight $(18.5$ to $\left.<25 \mathrm{~kg} / \mathrm{m}^{2}\right)$, overweight $\left(25\right.$ to $\left.<30 \mathrm{~kg} / \mathrm{m}^{2}\right)$, and obese $\left(\geq 30 \mathrm{~kg} / \mathrm{m}^{2}\right)$. We used the highest level of maternal education reported during pregnancy as a proxy for socioeconomic status [25]. Mothers self-reported one of five categories: none/CSE (certificate of secondary education), vocational (vocational courses after 16 years of age), O (ordinary level exams at 16 years), A (advanced level exams at 18 years), and university degree and above [26]. Ethnicity was based on maternal ethnicity and categorized as White or Other.

\subsection{Inclusion/Exclusion}

We included all participants that had liver enzyme measures (ALT, AST, and GGT serum concentrations) available at two of the four available time points $(9,15,17$, and 24 years) and that had valid transient elastography measures at 24 years. We excluded women who self-reported pregnancy at 17 or 24 years. We excluded the respondents with hazardous alcohol consumption defined by an Alcohol Use Disorder Identification Test for Consumption (AUDIT-C) score greater than or equal to 4 (women) and 5 (men) $[27,28]$.

\subsection{Statistical Analysis}

We calculated the median and interquartile range (IQR) values for continuous variables and counts and percentages for categorical variables for the full sample and stratified by level of hepatic steatosis (low, mild/moderate, or severe) at 24 years. Kruskal-Wallis tests were used to compare differences in continuous variables across steatosis levels. Chi-squared tests were used to compare differences between categorical variables. For cell counts less than five, Fisher's exact tests were used. We reported sex-stratified ALT, AST, and GGT medians and inter-quartile ranges by age and hepatic steatosis level at 24 years.

Due to non-normal distributions assessed by the Shapiro-Wilk test for normality, we analyzed ALT, AST, and GGT as log-transformed outcomes in all regression analyses. We used repeated-measures linear mixed models to assess the trend differences of log-transformed ALT, AST, and GGT levels from ages 9 to 24 years by hepatic steatosis level at 24 years. We also modeled differences of log-transformed ALT by fibrosis. We included the fixed effects for categorical age, random effects for the intercept, and an unstructured error covariance structure. To back-transform the log-transformed means from the models, we exponentiated them to geometric means. We then calculated geometric mean ratios (GMR) to assess the differences between steatosis levels at each age. Comparisons were made using Tukey-adjusted pairwise tests. We checked all model residuals for normality. 
We decided to conduct a sex-stratified analysis a priori. Covariates were adjusted for in a stepwise manner, whereby model 1 was unadjusted, model 2 included BMI at age 24 years as a covariate, and model 3 included maternal education and ethnicity as covariates.

A sensitivity analysis was performed to compare the characteristics of the original cohort to those in our analytic sample. In addition, to understand the impact of alcohol consumption, we (1) analyzed the association between high AUDIT-C score and hepatic steatosis, and (2) ran the models with the AUDIT-C score as a covariate instead of an exclusion criterion.

We conducted statistical analyses in SAS version 9.4 (Cary, NC, USA).

\section{Results}

Of the 10,018 active ALSPAC participants who were invited to participate in the Focus@24+ clinic, 3877 participants had Fibroscan performed (Figure 1). Of these, 3766 participants had a valid CAP score and 3600 participants had a valid fibrosis score. After exclusions for having ALT measures obtained on no or only one occasion $(n=590)$, pregnancy $(n=7)$, and high AUDIT-C score $(n=2013)$, our analytic sample size was 1156.

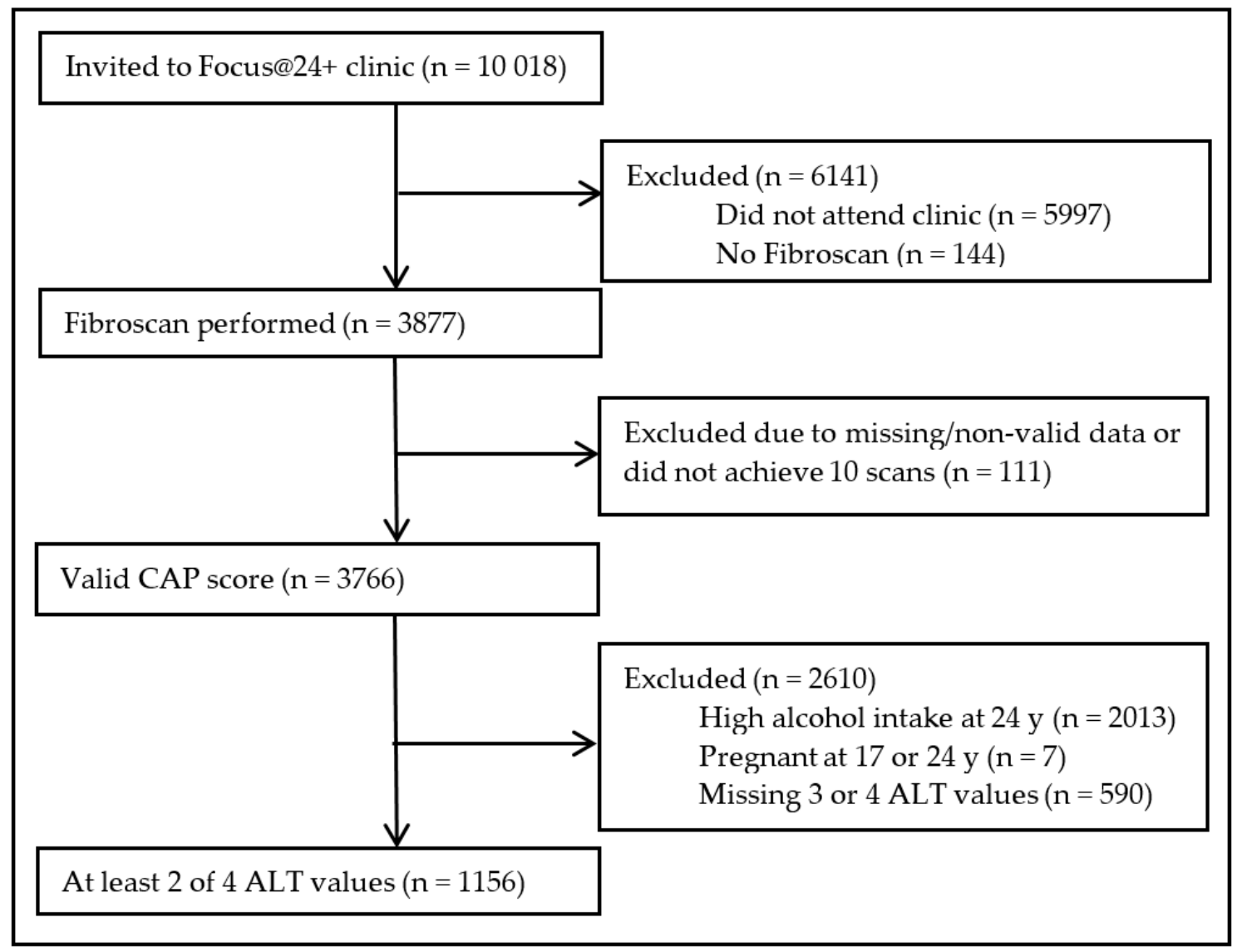

Figure 1. Flowchart of the participants included in final analysis. Of the 10,108 participants invited to Focus@24 year clinic, we excluded those that did not attend the clinic or did not get a liver scan because they were ineligible or excluded due to an active implant, liver ascites, or pregnancy. We also excluded participants with missing or non-valid controlled attenuation parameter (CAP) scores, who had a high alcohol intake, were pregnant at the 17 or 24 year clinic, and had less than 2 alanine aminotransferase (ALT) values measured at 9, 15, 17, and/or 24 years. Our final sample size was 1156.

Selected demographic and clinical characteristics of the study sample are presented in Table 1. Most of the participants were female (58.6\%) and reported being of White ethnicity (97.4\%). The majority $(77.8 \%)$ had low hepatic steatosis, but $11.9 \%$ had mild to moderate and $10.4 \%$ had severe hepatic 
steatosis (Table 1). There was a positive association between liver enzymes and hepatic steatosis at 24 years $(p<0.001)$. All the clinical biomarkers measured at 24 years had a positive association with hepatic steatosis, except for high-density lipoprotein (HDL) which had a negative association $(p<0.001)$. In sensitivity analysis, there was no association between high alcohol intake and hepatic steatosis level (Chi-square $=2.4, p=0.30$ ). Compared to those enrolled in the original cohort, participants in our sample were more likely to be female and have mothers with a higher education status (both $p<0.001$ ).

Table 1. Demographic and clinical factors at 24 years according to hepatic steatosis level $(n=1156)^{1}$.

\begin{tabular}{|c|c|c|c|c|c|}
\hline & $\begin{array}{c}\text { Total } \\
(n=1156)\end{array}$ & $\begin{array}{c}\text { Low } \\
(n=899 ; \\
77.8 \%)\end{array}$ & $\begin{array}{l}\text { Mild/Moderate } \\
\qquad(n=137 \\
11.9 \%)\end{array}$ & $\begin{array}{c}\text { Severe } \\
(n=120 \\
10.4 \%)\end{array}$ & $p$-Value \\
\hline Age & $24(23,35)$ & $24(23,25)$ & $24(24,24)$ & $24(23,25)$ & 0.751 \\
\hline \multicolumn{6}{|l|}{ Sex } \\
\hline Male & $479(41.4)$ & $348(38.7)$ & $65(47.5)$ & $66(55.0)$ & \\
\hline Female & $677(58.6)$ & $551(61.3)$ & $72(52.6)$ & $54(45.0)$ & $<0.001$ \\
\hline \multicolumn{6}{|l|}{ Ethnic Group } \\
\hline White & $1041(97.4)$ & $812(97.8)$ & $124(96.1)$ & 105 (95.5) & \\
\hline Other & $28(2.6)$ & $18(2.2)$ & $5(3.9)$ & $5(4.6)$ & 0.086 \\
\hline \multicolumn{6}{|l|}{ Mother's education } \\
\hline CSE/None & $111(10.4)$ & $83(10.0)$ & $17(13.3)$ & $11(11.5)$ & \\
\hline Vocational & $70(6.5)$ & $55(6.6)$ & $10(7.8)$ & $5(4.5)$ & \\
\hline O-level & $372(34.8)$ & $280(33.7)$ & 48 (37.5) & $44(39.6)$ & \\
\hline A-level & $327(30.6)$ & $266(32.0)$ & $32(25.0)$ & $29(26.1)$ & \\
\hline Degree & $190(17.8)$ & $147(17.7)$ & $21(16.4)$ & $22(19.8)$ & \\
\hline BMI, $\mathrm{kg} / \mathrm{m}^{2}$ & $23.6(21.2,27.0)$ & $22.8(20.7,25.3)$ & $27.4(24.5,29.9)$ & $32.1(28.5,35.9)$ & 0.580 \\
\hline \multicolumn{6}{|l|}{ BMI category } \\
\hline Underweight/Normal & $659(62.4)$ & $608(73.2)$ & $42(33.6)$ & $9(9.0)$ & $<0.001$ \\
\hline Overweight & $260(24.6)$ & $178(21.4)$ & $53(42.4)$ & $29(29.0)$ & \\
\hline Obese & $137(13.0)$ & $45(5.4)$ & $30(24.0)$ & $62(62.0)$ & \\
\hline $\mathrm{CAP}, \mathrm{dB} / \mathrm{m}$ & $204(175,242)$ & $193(166,213)$ & $261(255,270)$ & $313(292.5,343)$ & \\
\hline Fibrosis, kPA & $4.6(3.9,5.5)$ & $4.6(3.9,5.4)$ & $4.5(3.8,5.4)$ & $5(4,6)$ & $<0.001$ \\
\hline Any Fibrosis ${ }^{3}$ & $29(2.6)$ & $21(2.4)$ & $<5^{2}$ & $6(5.3)$ & \\
\hline ALT, U/L & $20.7(15.5,30.0)$ & $19.6(15.0,27.9)$ & $20.8(16.5,30.8)$ & $35.2(23.3,64.0)$ & $<0.001$ \\
\hline Elevated ALT & $437(41.0)$ & $308(36.8)$ & $52(41.3)$ & $77(75.5)$ & 0.015 \\
\hline AST, U/L & $23.9(20.5,29.3)$ & $23.4(20.3,28.6)$ & $24.4(20.0,28.5)$ & $29.3(23.9,36.7)$ & 0.175 \\
\hline GGT, U/L & $15.0(12.0,21.0)$ & $15.0(12.0,19.0)$ & $17.0(13.0,22.0)$ & $23.5(16.0,35.0)$ & $<0.001$ \\
\hline Cholesterol, mmol/L & $4.3(3.8,4.9)$ & $4.3(3.8,4.9)$ & $4.2(3.9,4.9)$ & $4.6(4.1,5.2)$ & $<0.001$ \\
\hline Triglycerides, $\mathrm{mmol} / \mathrm{L}$ & $0.8(0.6,1.1)$ & $0.8(0.6,1.1)$ & $0.9(0.7,1.2)$ & $1.1(0.8,1.9)$ & $<0.001$ \\
\hline $\mathrm{HDL}, \mathrm{mmol} / \mathrm{L}$ & $1.5(1.2,1.7)$ & $1.5(1.3,1.8)$ & $1.4(1.1,1.6)$ & $1.1(1,1.4)$ & $<0.001$ \\
\hline $\mathrm{LDL}, \mathrm{mmol} / \mathrm{L}$ & $2.4(1.9,2.9)$ & $2.4(1.9,2.9)$ & $2.4(2.2,3.2)$ & $2.8(2.3,3.2)$ & 0.004 \\
\hline $\mathrm{VLDL}, \mathrm{mmol} / \mathrm{L}$ & $0.4(0.3,0.5)$ & $0.4(0.3,0.5)$ & $0.4(0.3,0.5)$ & $0.5(0.4,0.8)$ & $<0.001$ \\
\hline Insulin, $\mathrm{mu} / \mathrm{L}$ & $7.7(5.4,11.3)$ & $7(5,9.7)$ & $10.8(7.2,15.2)$ & $16.6(10.8,25.1)$ & $<0.001$ \\
\hline Glucose, mmol/L & $5.3(5.0,5.6)$ & $5.3(5,5.6)$ & $5.4(5.1,5.7)$ & $5.5(5.3,5.8)$ & $<0.001$ \\
\hline
\end{tabular}

${ }^{1}$ Values represent the median (IQR) or number of participants (\%). Chi-squared tests were used to compare the differences between categorical variables. For cell counts $<5$, Fisher's exact tests were used. Kruskal-Wallis tests were used to compare the differences across steatosis levels for continuous variables. Some variables had missing values: ethnic group $(n=87)$, mother's highest education level $(n=86)$, BMI $(n=9)$, fibrosis $(n=56)$, and biomarker values $(n=91) .{ }^{2}$ Groups with less than five participants are expressed as $n<5$ in line with the Avon Longitudinal Study of Parents and Children (ALSPAC) confidentiality policy. ${ }^{3}$ Any fibrosis includes those with portal fibrosis, septa, or cirrhosis (F2-F4, >7.9 kPA). Abbreviations: CSE = certificate of secondary education, BMI = body mass index, $\mathrm{CAP}=$ controlled attenuation parameter, ALT $=$ alanine aminotransferase, AST $=$ aspartate aminotransferase, GGT = gamma-glutamyl transferase, $\mathrm{HDL}$ = high-density lipoprotein, $\mathrm{LDL}=$ low-density lipoprotein, $\mathrm{VLDL}=$ very low-density lipoprotein.

The trends of ALT, AST, and GGT over time differed across levels of steatosis for both sexes (Table 2). Figure 2 shows the geometric means and 95\% CIs of each liver enzyme plotted over time and stratified by steatosis level at 24 years for each sex from model 1. ALT values increased with age in both sexes, with strong evidence for higher ALT values in those with severe vs. low hepatic steatosis starting at 17 years in males and 24 years in females (Figure 2A,B, Table 3). AST levels 
declined in both sexes until 17 years when they started to increase. In both sexes, strong evidence for differences in AST between those with severe vs. low hepatic steatosis at 24 years were only apparent at 24 years and not in childhood and adolescence (Figure 2C,D, Table 3). In both sexes, GGT values were higher throughout childhood and into adulthood in those with severe vs. low steatosis at 24 years (Figure 2E,F). Adjusting for BMI at 24 years attenuated the estimates of differences in liver enzymes towards the null, although strong differences between those with severe vs. low hepatic steatosis levels remained at 24 years (Table 3). Additionally, adjusting for ethnicity and maternal education did not meaningfully change differences. Differences between all levels of hepatic steatosis and for models 1-3 are presented in Table S1. In males, ALT levels did not differ at any age between those with any vs. no fibrosis at 24 years (Figure 3A). In females, ALT levels were higher at 17 years, which was maintained at 24 years, in those with any vs. no fibrosis at 24 years (Figure 3B).

Table 2. ALT, AST, and GGT by age and hepatic steatosis at 24 years $(n=479 \text { males, } 677 \text { females })^{1}$.

\begin{tabular}{|c|c|c|c|c|c|}
\hline & 9 Years & 15 Years & 17 Years & 24 Years & $p$-Value \\
\hline Hepatic Steatosis & \multicolumn{4}{|c|}{ ALT, U/L } & \\
\hline Males & & & & & $<0.001$ \\
\hline Low & $11.8(9.0,15.3)$ & $16.9(13.5,20.6)$ & $15.0(12.3,20.6)$ & $24.4(18.2,32.8)$ & \\
\hline Mild/Moderate & $11.8(8.5,16.0)$ & $17.5(14.1,22.7)$ & $17.7(13.0,21.2)$ & $28.2(20.6,39.7)$ & \\
\hline Severe & $11.9(8.8,14.0)$ & $17.9(14.2,23.5)$ & $22.6(15.3,30.4)$ & $46.8(34.6,73.3)$ & \\
\hline Females & & & & & $<0.001$ \\
\hline Low & $11.7(9.2,14.8)$ & $13.5(10.6,17.0)$ & $13.7(11.1,17.2)$ & $17.2(13.4,23.0)$ & \\
\hline Mild/Moderate & $11.2(8.8,13.9)$ & $13.8(10.9,16.1)$ & $14.5(11.3,20.1)$ & $16.9(14.7,23.6)$ & \\
\hline \multirow[t]{2}{*}{ Severe } & $12.0(8.6,15.0)$ & $13.1(9.9,19.2)$ & $15.9(12.3,27.2)$ & $25.4(17.9,32.9)$ & \\
\hline & \multicolumn{4}{|c|}{ AST, U/L } & \\
\hline Males & & & & & $<0.001$ \\
\hline Low & $32.1(28.4,35.6)$ & $22.9(19.6,26.9)$ & $20.2(17.2,23.4)$ & $26.1(21.7,31.2)$ & \\
\hline Mild/Moderate & $30.8(28.0,34.2)$ & $23.1(20.8,29.4)$ & $20.5(17.5,27.1)$ & $26.5(24.1,31.6)$ & \\
\hline Severe & $32.0(28.2,35.3)$ & $22.9(19.9,27.4)$ & $21.7(18.2,25.6)$ & $33.8(25.9,38.7)$ & \\
\hline Females & & & & & $<0.001$ \\
\hline Low & $30.5(27.1,34.7)$ & $19.5(17.2,22.0)$ & $18.6(16.2,22.0)$ & $22.2(19.5,26.0)$ & \\
\hline Mild/Moderate & $29.4(27.1,33.3)$ & $18.5(16.4,21.7)$ & $17.8(15.5,22.2)$ & $21.9(18.9,26.0)$ & \\
\hline \multirow[t]{2}{*}{ Severe } & $29.1(25.8,32.2)$ & $19.2(15.7,22.3)$ & $17.6(16.6,21.9)$ & $25.5(22.2,31.3)$ & \\
\hline & \multicolumn{4}{|c|}{ GGT, U/L } & \\
\hline Males & & & & & $<0.001$ \\
\hline Low & $15.0(14.0,18.0)$ & $16.0(14.0,18.0)$ & $17.0(14.0,21.0)$ & $16.0(14.0,21.0)$ & \\
\hline Mild/Moderate & $17.0(14.0,22.0)$ & $17.0(15.0,23.0)$ & $21.0(16.0,25.0)$ & $20.5(15.0,30.5)$ & \\
\hline Severe & $17.0(14.0,22.0)$ & $19.0(16.0,23.0)$ & $21.0(16.0,32.0)$ & $27.0(19.0,38.0)$ & \\
\hline Females & & & & & 0.002 \\
\hline Low & $15.0(13.0,18.0)$ & $14.0(11.0,16.0)$ & $14.0(12.0,18.0)$ & $14.0(11.0,18.0)$ & \\
\hline Mild/Moderate & $16.0(14.0,20.0)$ & $14.0(12.0,19.0)$ & $17.0(13.0,22.0)$ & $14.0(12.0,18.0)$ & \\
\hline Severe & $18.0(14.0,22.0)$ & $14.0(12.0,19.0)$ & $17.0(13.0,20.0)$ & $19.0(14.0,31.0)$ & \\
\hline
\end{tabular}



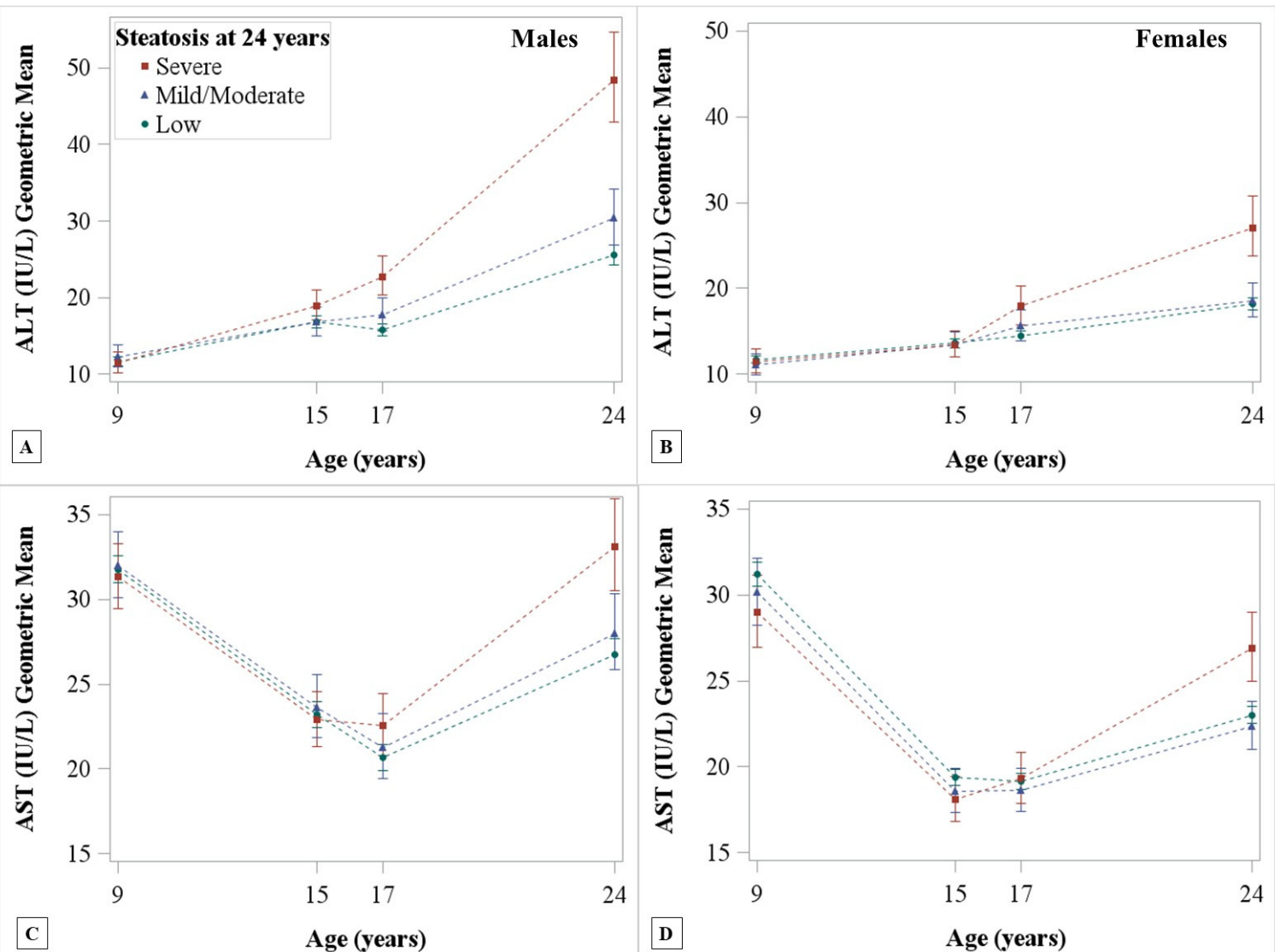

B Age (years)
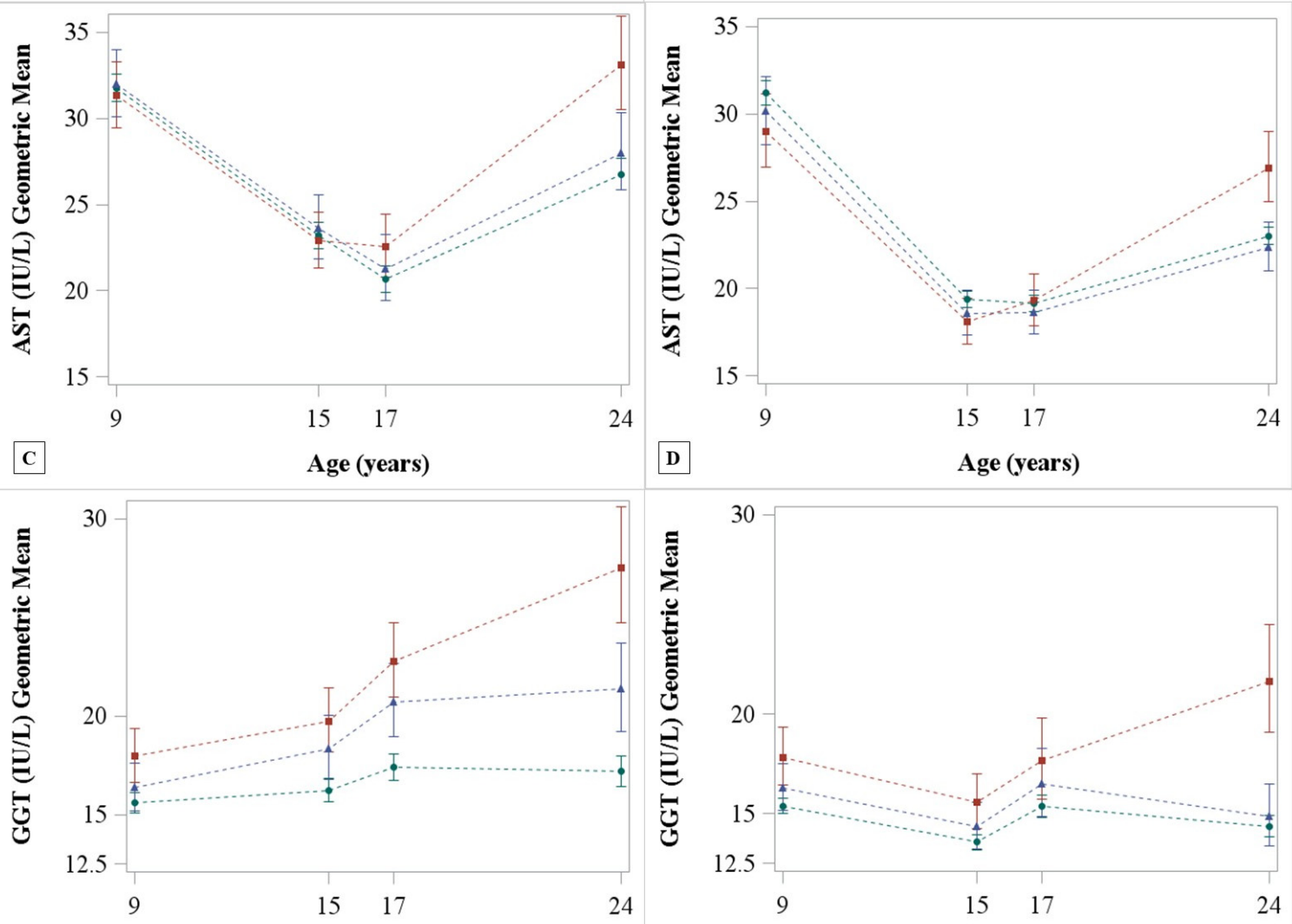

E

Age (years)

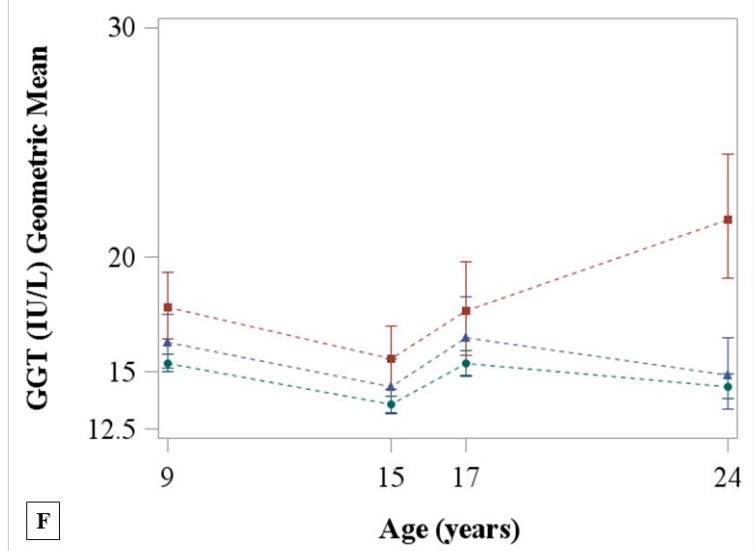

Figure 2. ALT, AST, GGT geometric mean and $95 \%$ CI trends by hepatic steatosis level and sex. Sample size was 479 males $(\mathbf{A}, \mathbf{C}, \mathbf{E})$ and 677 females $(\mathbf{B}, \mathbf{D}, \mathbf{F})$. Steatosis is defined from controlled attenuation parameter scores: low $(<248 \mathrm{~dB} / \mathrm{m})$, mild/moderate $(248-279 \mathrm{~dB} / \mathrm{m})$, severe $(>279 \mathrm{~dB} / \mathrm{m})$. Low is marked by filled green circles, mild/moderate by blue filled triangles, and severe by filled red squares. 
Table 3. Geometric mean ratios and $95 \%$ CIs of liver enzymes for low vs. severe hepatic steatosis level at each age (years) and by sex ${ }^{1}$.

\begin{tabular}{ccccc}
\hline & \multicolumn{2}{c}{ Males $(n=479)$} & \multicolumn{2}{c}{ Females $(n=677)$} \\
\hline ALT & Unadjusted & Fully Adjusted ${ }^{2}$ & Unadjusted & ${\text { Fully Adjusted }{ }^{2}}^{2}$ \\
\hline 9 years & $1.02(0.82,1.27)$ & $1.15(0.90,1.48)$ & $1.02(0.82,1.26)$ & $1.13(0.89,1.44)$ \\
15 years & $0.89(0.74,1.07)$ & $1.01(0.81,1.26)$ & $1.01(0.83,1.24)$ & $1.15(0.91,1.45)$ \\
17 years & $0.69(0.57,0.85)$ & $0.8(0.64,1.01)$ & $0.81(0.65,1.01)$ & $1.01(0.79,1.29)$ \\
24 years & $0.53(0.42,0.66)$ & $0.63(0.5,0.81)$ & $0.67(0.54,0.84)$ & $0.75(0.59,0.96)$ \\
\hline AST & & & & \\
\hline 9 years & $1.01(0.91,1.13)$ & $1.03(0.91,1.18)$ & $1.08(0.95,1.22)$ & $1.08(0.93,1.24)$ \\
15 years & $1.01(0.89,1.15)$ & $1.02(0.88,1.19)$ & $1.07(0.94,1.22)$ & $1.02(0.88,1.18)$ \\
17 years & $0.92(0.79,1.06)$ & $0.93(0.79,1.10)$ & $0.99(0.87,1.13)$ & $1.02(0.88,1.18)$ \\
24 years & $0.81(0.70,0.94)$ & $0.86(0.72,1.01)$ & $0.86(0.75,0.97)$ & $0.84(0.73,0.97)$ \\
\hline GGT & & & & \\
\hline 9 years & $0.87(0.76,1.00)$ & $1.01(0.86,1.18)$ & $0.86(0.75,0.99)$ & $1.00(0.85,1.18)$ \\
15 years & $0.82(0.71,0.96)$ & $0.99(0.85,1.16)$ & $0.87(0.75,1.02)$ & $0.99(0.82,1.19)$ \\
17 years & $0.76(0.66,0.89)$ & $0.90(0.75,1.07)$ & $0.87(0.71,1.07)$ & $1.03(0.82,1.30)$ \\
24 years & $0.62(0.51,0.76)$ & $0.73(0.59,0.89)$ & $0.66(0.53,0.83)$ & $0.77(0.61,0.98)$ \\
\hline
\end{tabular}

${ }^{1}$ Steatosis is defined from controlled attenuation parameter scores: low $(<248 \mathrm{~dB} / \mathrm{m})$, mild/moderate $(248-279 \mathrm{~dB} / \mathrm{m})$, severe $(>279 \mathrm{~dB} / \mathrm{m}) .{ }^{2}$ Adjusted for BMI at 24 years, maternal ethnicity and education. Abbreviations: ALT = alanine aminotransferase, AST = aspartate aminotransferase, GGT = gamma-glutamyl transferase.
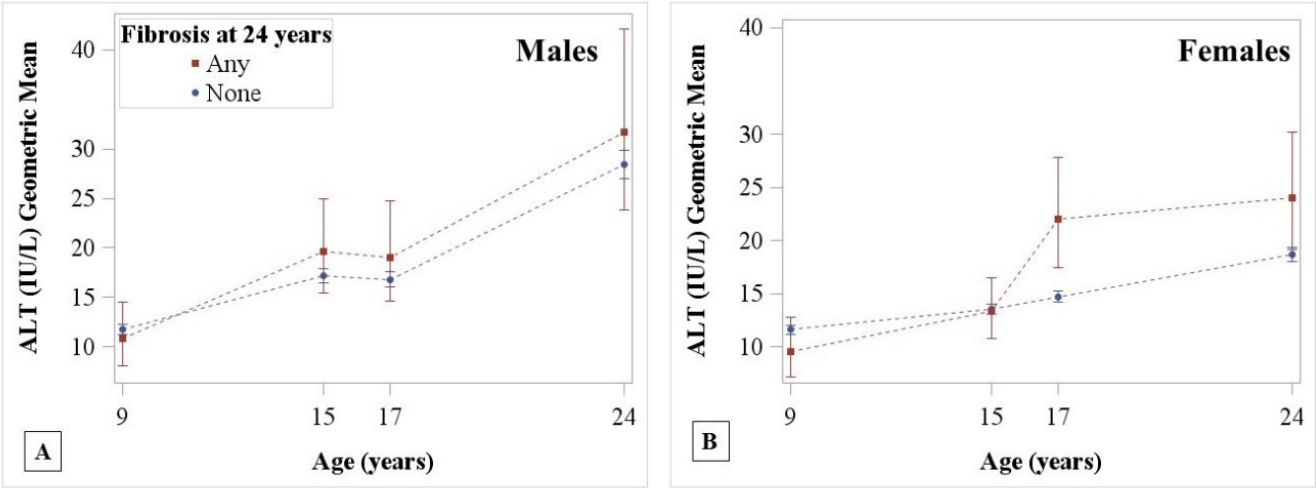

Figure 3. ALT geometric mean trends by fibrosis category and sex. (A) In males, and (B) in females. Any fibrosis (red square) includes those with portal fibrosis, septa, or cirrhosis (F2-F4, >7.9 kPA).

In the sensitivity analysis, controlling for alcohol intake using the AUDIT-C score, instead of excluding those with hazardous alcohol intake, did not meaningfully change estimates (Table S2).

\section{Discussion}

We found that young adults with severe hepatic steatosis as measured by CAP had a steeper ALT trend from 9 to 24 years compared to those with low hepatic steatosis, with the largest increase occurring from the late teen to young adult years. In males, the differentiation of ALT trends appears to coincide with the beginning of puberty. The association between puberty and increases in steatosis and ALT has been described in previous studies [29,30]. In girls, differences in trend first appeared in late adolescence and with stronger differences occurring in young adulthood. Interestingly, girls with mild/moderate and low steatosis had nearly identical trajectories for ALT, perhaps indicating that ALT is not as sensitive of an indicator in girls, unless they have severe steatosis. NAFLD is known to be a sexually dimorphic disease. Evidence specific to young women indicates that they are better able to partition fatty acids towards ketone body production rather than very-low-density lipoprotein 
(VLDL)-triacylglycerol packaging compared to young men, leading to protection from dysmetabolic conditions such as NAFLD [31,32].

Concentrations of GGT were consistently higher in those with severe vs. low steatosis over time. However, we found that most associations, particularly for GGT, were attenuated after controlling for BMI at 24 years. The strong association of BMI with ALT and GGT has been previously shown $[30,33]$. This finding supports the current recommendation that screening for NAFLD be performed using elevated ALT in at-risk populations including overweight and obese children and adolescents [2]. ALT is an inexpensive, widely available, minimally invasive blood test with acceptable sensitivity, making it a useful screening tool in at-risk pediatric populations [2]. Additionally, these results indicate that more research should be conducted to see if GGT should play a larger role for NAFLD screening in childhood and adolescence.

At 24 years, $10.4 \%$ of the ALSPAC sample had severe and $11.9 \%$ had mild or moderate hepatic steatosis. Abeysekera, et al., using the same cohort, also found a similar $20.7 \%$ prevalence of steatosis [34]. This represents a large increase from a NAFLD prevalence of $2.5 \%$ (defined as moderate or severe steatosis) in the cohort as measured by ultrasound at the age of $17-18$ years $[34,35]$. This likely partially reflects a true increase in the prevalence. Other possible explanations for the increased prevalence include selection bias and poorer diagnostic ability of the ultrasound technology compared to transient elastography and CAP measures for the assessment of hepatic steatosis. Estimates of the prevalence of NAFLD in adolescents in the US and Australia defined by a variety of methods including autopsy, ultrasound, and ALT, range from $10 \%$ to $17 \%[3,29,36]$.

Heavy alcohol consumption is of concern in young adults, particularly in the UK [37]. Approximately half of the sample reported hazardous alcohol consumption at 24 years, a known risk factor for hepatic steatosis. To limit potential confounding by alcohol consumption, we excluded all participants with an elevated AUDIT-C score, an instrument used to identify hazardous drinkers. Our criteria led to the exclusion of almost half the sample, therefore, we conducted a sensitivity analysis including participants with any level of drinking and controlling for the AUDIT-C score. We found no meaningful changes to our results. Similar to Abeysekera, et al., we also found no evidence of an association between hazardous alcohol consumption and hepatic steatosis [34]. Future studies should focus on the impact of high alcohol consumption in this population on hepatic steatosis, fibrosis, and other health outcomes.

The largest strength of our study was the use of serial measurements in a large, population-based longitudinal cohort study from childhood to young adulthood. We also used the CAP score based on transient elastography to define hepatic steatosis levels at 24 years, which is a validated and accurate marker of hepatic steatosis in adults [22]. An additional strength is the use of the AUDIT-C score to exclude individuals with hazardous alcohol consumption, increasing our confidence that participants in our analysis with severe hepatic steatosis had non-alcoholic fatty liver disease. The AUDIT-C has been shown to perform well among adolescents with good internal consistency and accuracy [38]. The AUDIT-C has also been shown to be more useful than the AST/ALT ratio, an indicator of alcoholic fatty liver disease (vs. NAFLD), for predicting hazardous drinking [39].

While we did not exclude participants with other liver conditions, a previous report from this population reported that no participants had viral hepatitis or were taking nucleos(t)ide analogues or direct-acting antivirals and very few were taking medications for autoimmune hepatitis [34]. Therefore, we are confident that there was little, if any, confounding by other liver disease.

A limitation of this study was the relatively homogenous nature of the sample, of primarily White ethnicity, and therefore, results may not be generalizable to other populations. We expect that the associations we found would differ in samples with a larger proportion of higher-risk individuals, such as Hispanics [40]. Individuals with adipogenic genes such as Patatin-like phospholipase domain-containing protein 3 (PNPLA3), which is more common in Hispanics, are more susceptible to NAFLD [41]. Additionally, there was differential loss to follow-up within the cohort, whereby females and participants with mothers with higher education were more likely to be followed-up. 


\section{Conclusions}

This is the first description of liver enzyme trends extending from childhood to adulthood and their relation with later hepatic steatosis. ALT trends were associated with hepatic steatosis level in young adulthood. Higher ALT and GGT levels in adolescence were associated with severe hepatic steatosis at 24 years, whereas, prior to puberty, liver enzymes may not be a useful indicator of future risk. The increased testing of liver enzymes in adolescents could strengthen early NAFLD prevention and treatment efforts. There is a need for further quality longitudinal data on the natural history of pediatric NAFLD.

Supplementary Materials: The following are available online at http://www.mdpi.com/2227-9067/7/9/117/s1, Table S1: Geometric mean ratios and $95 \%$ CIs of liver enzymes for hepatic steatosis levels at each age stratified by sex, Table S2: Geometric mean ratios and 95\% CIs of liver enzymes for hepatic steatosis levels at each age stratified by sex including participants regardless of AUDIT-C.

Author Contributions: Conceptualization, M.B.V. and A.S.; data curation, A.S., J.A.W. and K.N.; formal analysis, A.S. and J.F.; methodology, A.S., K.N., C.E.C., A.D.S., and J.F.; project administration, A.S.; resources, M.B.V.; supervision, J.A.W., K.N., A.D.S., U.R., M.B.V.; visualization, A.S.; writing-original draft, A.S.; writing-review and editing, A.S., J.A.W., K.N., C.E.C., A.D.S., J.F., U.R., and M.B.V. All authors have read and agreed to the published version of the manuscript.

Funding: The UK Medical Research Council and Wellcome (Grant ref: 217065/Z/19/Z) and the University of Bristol provide core support for ALSPAC. This publication is the work of the authors, who serve as guarantors for the contents of this paper. A comprehensive list of grants funding is available on the ALSPAC website (http://www.bristol.ac.uk/alspac/external/documents/grant-acknowledgements.pdf). This research was specifically funded by the UK Medical Research Council (MRC) (MR/L022206/1, G0801456). Support for procurement of the data was provided by Children's Healthcare of Atlanta, GA, USA.

Acknowledgments: We are extremely grateful to all the families who took part in this study, the midwives for their help in recruiting them, and the whole ALSPAC team, which includes interviewers, computer and laboratory technicians, clerical workers, research scientists, volunteers, managers, receptionists and nurses.

Conflicts of Interest: The funders had no role in the design of the study; in the collection, analyses, or interpretation of data; in the writing of the manuscript, or in the decision to publish the results. M.B.V. reports personal fees from Intercept, grants from Immuron, grants and personal fees from Target Pharmasolutions, personal fees from Boehringer Ingelheim, grants and personal fees from Bristol Myers Squibb, personal fees from Prosciento, and personal fees from Novo Nordisk during the conduct of the study. A.D.S. reports grants from NIH and from the Bill and Melinda Gates Foundation unrelated to the subject matter of this paper.

\section{References}

1. Chalasani, N.; Younossi, Z.; Lavine, J.E.; Diehl, A.M.; Brunt, E.M.; Cusi, K.; Charlton, M.; Sanyal, A.J. The diagnosis and management of non-alcoholic fatty liver disease: Practice guideline by the American Gastroenterological Association, American Association for the Study of Liver Diseases, and American College of Gastroenterology. Gastroenterology 2012, 142, 1592-1609. [CrossRef]

2. Vos, M.B.; Abrams, S.H.; Barlow, S.E.; Caprio, S.; Daniels, S.R.; Kohli, R.; Mouzaki, M.; Sathya, P.; Schwimmer, J.B.; Sundaram, S.S. NASPGHAN clinical practice guideline for the diagnosis and treatment of nonalcoholic fatty liver disease in children: Recommendations from the expert committee on NAFLD (ECON) and the North American Society of Pediatric Gastroenterology, Hepatology and Nutrition (NASPGHAN). J. Pediatr. Gastroenterol. Nutr. 2017, 64, 319-334. [PubMed]

3. Welsh, J.A.; Karpen, S.; Vos, M.B. Increasing Prevalence of Nonalcoholic Fatty Liver Disease Among United States Adolescents, 1988-1994 to 2007-2010. J. Pediatr. 2013, 162, 496-500. [CrossRef] [PubMed]

4. Feldstein, A.E.; Charatcharoenwitthaya, P.; Treeprasertsuk, S.; Benson, J.T.; Enders, F.B.; Angulo, P. The natural history of non-alcoholic fatty liver disease in children: A follow-up study for up to 20 years. Gut 2009, 58, 1538-1544. [CrossRef]

5. Vernon, G.; Baranova, A.; Younossi, Z. Systematic review: The epidemiology and natural history of non-alcoholic fatty liver disease and non-alcoholic steatohepatitis in adults. Aliment. Pharmacol. Ther. 2011, 34, 274-285. [CrossRef] [PubMed]

6. Hagström, H.; Höijer, J.; Ludvigsson, J.F.; Bottai, M.; Ekbom, A.; Hultcrantz, R.; Stephansson, O.; Stokkeland, K. Adverse outcomes of pregnancy in women with non-alcoholic fatty liver disease. Liver Int. 2016, 36, 268-274. [CrossRef] [PubMed] 
7. Patel, K.R.; White, F.V.; Deutsch, G.H. Hepatic steatosis is prevalent in stillborns delivered to women with diabetes mellitus. J. Pediatr. Gastroenterol. Nutr. 2015, 60, 152-158. [CrossRef] [PubMed]

8. Modi, N.; Murgasova, D.; Ruager-Martin, R.; Thomas, E.L.; Hyde, M.J.; Gale, C.; Santhakumaran, S.; Doré, C.J.; Alavi, A.; Bell, J.D. The Influence of Maternal Body Mass Index on Infant Adiposity and Hepatic Lipid Content. Pediatr. Res. 2011, 70, 287. [CrossRef]

9. Brumbaugh, D.E.; Tearse, P.; Cree-Green, M.; Fenton, L.Z.; Brown, M.; Scherzinger, A.; Reynolds, R.; Alston, M.; Hoffman, C.; Pan, Z.; et al. Intrahepatic Fat is Increased in Neonatal Offspring of Obese Women with Gestational Diabetes. J. Pediatr. 2013, 162, 930-936. [CrossRef] [PubMed]

10. Bleeker, J.C.; Visser, G.; Wijburg, F.A.; Ferdinandusse, S.; Waterham, H.R.; Nikkels, P.G. Severe fat accumulation in multiple organs in pediatric autopsies: An uncommon but significant finding. Pediatr. Dev. Pathol. 2017, 20, 269-276. [CrossRef]

11. Goyal, N.P.; Schwimmer, J.B. The progression and natural history of pediatric nonalcoholic fatty liver disease. Clin. Liver Dis. 2016, 20, 325-338. [CrossRef] [PubMed]

12. Schwimmer, J.B.; Ugalde-Nicalo, P.; Welsh, J.A.; Angeles, J.E.; Cordero, M.; Harlow, K.E.; Alazraki, A.; Durelle, J.; Knight-Scott, J.; Newton, K.P.; et al. Effect of a low free sugar diet vs usual diet on nonalcoholic fatty liver disease in adolescent boys: A randomized clinical trial. JAMA 2019, 321, 256-265. [CrossRef] [PubMed]

13. Schwimmer, J.B.; Newton, K.P.; Awai, H.I.; Choi, L.J.; Garcia, M.A.; Ellis, L.L.; Vanderwall, K.; Fontanesi, J. Paediatric gastroenterology evaluation of overweight and obese children referred from primary care for suspected non-alcoholic fatty liver disease. Aliment. Pharmacol. Ther. 2013, 38, 1267-1277. [CrossRef] [PubMed]

14. Boyd, A.; Golding, J.; Macleod, J.; Lawlor, D.A.; Fraser, A.; Henderson, J.; Molloy, L.; Ness, A.; Ring, S.; Davey Smith, G. Cohort profile: The 'children of the 90s' - The index offspring of the Avon Longitudinal Study of Parents and Children. Int. J. Epidemiol. 2013, 42, 111-127. [CrossRef]

15. Fraser, A.; Macdonald-Wallis, C.; Tilling, K.; Boyd, A.; Golding, J.; Davey Smith, G.; Henderson, J.; Macleod, J.; Molloy, L.; Ness, A. Cohort profile: The Avon Longitudinal Study of Parents and Children: ALSPAC mothers cohort. Int. J. Epidemiol. 2012, 42, 97-110. [CrossRef]

16. Northstone, K.; Lewcock, M.; Groom, A.; Boyd, A.; Macleod, J.; Timpson, N.; Wells, N. The Avon Longitudinal Study of Parents and Children (ALSPAC): An update on the enrolled sample of index children in 2019 [version 1; peer review: 2 approved]. Wellcome Open Res. 2019, 4, 51. [CrossRef]

17. Harris, P.A.; Taylor, R.; Thielke, R.; Payne, J.; Gonzalez, N.; Conde, J.G. A metadata-driven methodology and workflow process for providing translational research informatics support. J. Biomed. Inform. 2009, 42, 377-381. [CrossRef]

18. Harris, P.A.; Taylor, R.; Minor, B.L.; Elliott, V.; Fernandez, M.; O’Neal, L.; McLeod, L.; Delacqua, G.; Delacqua, F.; Kirby, J. The REDCap consortium: Building an international community of software platform partners. J. Biomed. Inform. 2019, 95, 103208. [CrossRef]

19. Bristol, U.O. Explore Data and Samples. Available online: http://www.bristol.ac.uk/alspac/researchers/ourdata/ (accessed on 6 December 2019).

20. O'Keeffe, L.M.; Simpkin, A.J.; Tilling, K.; Anderson, E.L.; Hughes, A.D.; Lawlor, D.A.; Fraser, A.; Howe, L.D. Data on trajectories of measures of cardiovascular health in the Avon Longitudinal Study of Parents and Children (ALSPAC). Data Brief 2019, 23, 103687. [CrossRef]

21. Prati, D.; Taioli, E.; Zanella, A.; Della Torre, E.; Butelli, S.; Del Vecchio, E.; Vianello, L.; Zanuso, F.; Mozzi, F.; Milani, S. Updated definitions of healthy ranges for serum alanine aminotransferase levels. Ann. Intern. Med. 2002, 137, 1-10. [CrossRef]

22. Karlas, T.; Petroff, D.; Sasso, M.; Fan, J.; Mi, Y.; de Lédinghen, V.; Kumar, M.; Lupsor-Platon, M.; Han, K.; Cardoso, A.C. Individual patient data meta-analysis of controlled attenuation parameter (CAP) technology for assessing steatosis. J. Hepatol. 2017, 66, 1022-1030. [CrossRef] [PubMed]

23. Wong, V.W.S.; Vergniol, J.; Wong, G.L.H.; Foucher, J.; Chan, H.L.Y.; Le Bail, B.; Choi, P.C.L.; Kowo, M.; Chan, A.W.H.; Merrouche, W. Diagnosis of fibrosis and cirrhosis using liver stiffness measurement in nonalcoholic fatty liver disease. Hepatology 2010, 51, 454-462. [CrossRef] [PubMed]

24. National Heart, Lung, Blood Institute, \& North American Association for the Study of Obesity. The Practical Guide: Identification, Evaluation, and Treatment of Overweight and Obesity in Adults; National Institutes of Health, National Heart, Lung, and Blood Institute: Bethesda, MD, USA, 2000. 
25. Bigornia, S.J.; LaValley, M.P.; Noel, S.E.; Moore, L.L.; Ness, A.R.; Newby, P.K. Sugar-sweetened beverage consumption and central and total adiposity in older children: A prospective study accounting for dietary reporting errors. Public Health Nutr. 2015, 18, 1155-1163. [CrossRef]

26. Howe, L.D.; Tilling, K.; Galobardes, B.; Smith, G.D.; Ness, A.R.; Lawlor, D.A. Socioeconomic disparities in trajectories of adiposity across childhood. Int. J. Pediatr. Obes. 2011, 6, 144-153. [CrossRef] [PubMed]

27. Association, A.P. Diagnostic and Statistical Manual of Mental Disorders (DSM-5 ${ }^{\circledR}$ ); American Psychiatric Pub.: Washington, DC, USA, 2013.

28. Kriston, L.; Hölzel, L.; Weiser, A.-K.; Berner, M.M.; Härter, M. Meta-analysis: Are 3 Questions Enough to Detect Unhealthy Alcohol Use? Ann. Intern. Med. 2008, 149, 879-888. [CrossRef]

29. Schwimmer, J.B.; Deutsch, R.; Kahen, T.; Lavine, J.E.; Stanley, C.; Behling, C. Prevalence of fatty liver in children and adolescents. Pediatrics 2006, 118, 1388-1393. [CrossRef]

30. Bussler, S.; Vogel, M.; Pietzner, D.; Harms, K.; Buzek, T.; Penke, M.; Händel, N.; Körner, A.; Baumann, U.; Kiess, W. New pediatric percentiles of liver enzyme serum levels (alanine aminotransferase, aspartate aminotransferase, $\gamma$-glutamyltransferase): Effects of age, sex, body mass index, and pubertal stage. Hepatology 2018, 68, 1319-1330. [CrossRef]

31. Ballestri, S.; Nascimbeni, F.; Baldelli, E.; Marrazzo, A.; Romagnoli, D.; Lonardo, A. NAFLD as a sexual dimorphic disease: Role of gender and reproductive status in the development and progression of nonalcoholic fatty liver disease and inherent cardiovascular risk. Adv. Ther. 2017, 34, 1291-1326. [CrossRef]

32. Marinou, K.; Adiels, M.; Hodson, L.; Frayn, K.N.; Karpe, F.; Fielding, B.A. Young women partition fatty acids towards ketone body production rather than VLDL-TAG synthesis, compared with young men. Br. J. Nutr. 2011, 105, 857-865. [CrossRef]

33. Lee, S.Y.; Sung, E.; Chang, Y. Elevated serum gamma-glutamyltransferase is a strong marker of insulin resistance in obese children. Int. J. Endocrinol. 2013, 2013, 95-113. [CrossRef]

34. Abeysekera, K.W.; Fernandes, G.S.; Hammerton, G.; Portal, A.J.; Gordon, F.H.; Heron, J.; Hickman, M. Prevalence of steatosis and fibrosis in young adults in the UK: A population-based study. Lancet Gastroenterol. Hepatol. 2020, 5, 295-305. [CrossRef]

35. Lawlor, D.A.; Callaway, M.; Macdonald-Wallis, C.; Anderson, E.; Fraser, A.; Howe, L.D.; Day, C.; Sattar, N. Nonalcoholic fatty liver disease, liver fibrosis, and cardiometabolic risk factors in adolescence: A cross-sectional study of 1874 general population adolescents. J. Clin. Endocrinol. Metab. 2014, 99, 410-417. [CrossRef] [PubMed]

36. Ayonrinde, O.T.; Olynyk, J.K.; Marsh, J.A.; Beilin, L.J.; Mori, T.A.; Oddy, W.H.; Adams, L.A. Childhood adiposity trajectories and risk of nonalcoholic fatty liver disease in adolescents. J. Gastroenterol. Hepatol. 2015, 30, 163-171. [CrossRef] [PubMed]

37. Leon, D.A.; McCambridge, J. Liver cirrhosis mortality rates in Britain from 1950 to 2002: An analysis of routine data. Lancet 2006, 367, 52-56. [CrossRef]

38. Liskola, J.; Haravuori, H.; Lindberg, N.; Niemelä, S.; Karlsson, L.; Kiviruusu, O.; Marttunen, M. AUDIT and AUDIT-C as screening instruments for alcohol problem use in adolescents. Drug Alcohol Depend. 2018, 188, 266-273. [CrossRef] [PubMed]

39. Fujii, H.; Nishimoto, N.; Yamaguchi, S.; Kurai, O.; Miyano, M.; Ueda, W.; Oba, H.; Aoki, T.; Kawada, N.; Okawa, K. The Alcohol Use Disorders Identification Test for Consumption (AUDIT-C) is more useful than pre-existing laboratory tests for predicting hazardous drinking: A cross-sectional study. BMC Public Health 2016, 16, 379. [CrossRef]

40. Elizondo-Montemayor, L.; Ugalde-Casas, P.A.; Lam-Franco, L.; Bustamante-Careaga, H.; Serrano-González, M.; Gutiérrez, N.G.; Martínez, U. Association of ALT and the metabolic syndrome among Mexican children. Obes. Res. Clin. Pract. 2014, 8, 79-87. [CrossRef]

41. Romeo, S.; Kozlitina, J.; Xing, C.; Pertsemlidis, A.; Cox, D.; Pennacchio, L.A.; Boerwinkle, E.; Cohen, J.C.; Hobbs, H.H. Genetic variation in PNPLA3 confers susceptibility to nonalcoholic fatty liver disease. Nat. Genet. 2008, 40, 1461. [CrossRef]

(C) 2020 by the authors. Licensee MDPI, Basel, Switzerland. This article is an open access article distributed under the terms and conditions of the Creative Commons Attribution (CC BY) license (http://creativecommons.org/licenses/by/4.0/). 